\title{
Münkner, Jörn, Eingreifen und Begreifen. Handhabung und Visualisierung in Flugblättern der Frühen Neuzeit
}

\section{Naïma Ghermani}

\section{OpenEdition}

\section{Journals}

Édition électronique

URL : http://journals.openedition.org/ifha/2210

DOI : $10.4000 /$ ifha. 2210

ISSN : 2198-8943

Éditeur

IFRA - Institut franco-allemand (sciences historiques et sociales)

Référence électronique

Naïma Ghermani, « Münkner, Jörn, Eingreifen und Begreifen. Handhabung und Visualisierung in

Flugblättern der Frühen Neuzeit », Revue de l'IFHA [En ligne], Date de recension, mis en ligne le 01 janvier 2010, consulté le 22 septembre 2020. URL : http://journals.openedition.org/ifha/2210 ; DOI : https:// doi.org/10.4000/ifha. 2210

Ce document a été généré automatiquement le 22 septembre 2020.

(C)IFHA 


\title{
Münkner, Jörn, Eingreifen und Begreifen. Handhabung und Visualisierung in Flugblättern der Frühen Neuzeit
}

\author{
Naïma Ghermani
}

1 Les feuilles volantes sont depuis près de quarante ans l'objet de recherches nombreuses et surtout très variées. Support d'événements exceptionnels, de pamphlets, de poésies satiriques, et d'images en tous genres, les Flugblätter ont été dûment recensés et analysés aussi bien par des historiens, des historiens d'art que des littéraires. Ce livre issu d'un projet collectif sous la direction du germaniste Horst Wenzel, intitulé " Lisibilité du monde » entend au contraire envisager ce support sous l'angle d'une part de la " médiologie ", une discipline très en vogue outre-Rhin, et d'autre part sous l'angle des « techniques culturelles» (Kulturtechniken). Au cœur de ce travail se trouve l'idée du maniement des objets (Handhabung qui a pour deuxième sens la manipulation au sens propre et figuré).

2 D'emblée, donc, les feuilles volantes sont envisagées comme des médias, des outils de communication, sans que pour autant la pertinence de tels concepts pour des sources des XVIe et XVIIe siècles ne soit vraiment justifiée. Ce n'est pas faute, pourtant, de définir les sujets et les notions employés. Ainsi, les feuilles volantes sont indistinctement regroupées sous la catégories des «médias », sans faire valoir qu'elles sont des objets produits par des acteurs précis s'adressant à des groupes sociaux très particuliers en fonction de stratégies politiques, confessionnelles ou encore littéraires. Les concepts donc de « médium et médial » sont reliés à la définition qu'en fait Sybille Krämer ; ils renvoient aux " conditions de possibilité d'un événement et à la performance de production de formes et de concrétions perceptibles par les sens » (p. 18), car la «transmission d'une représentation symbolique du monde ne peut se faire que si on la situe matériellement " (ibid.). Quant aux techniques culturelles, elles embrassent « un large spectre de déroulement d'une activité, de modes de procédés et 
d'orthopratiques routinières que l'on peut apprendre, sur lesquelles on peut s'exercer de manière modulable et que l'on peut étudier ». Il s'agit donc de relier une forme visuelle à une activité du corps.

3 Pour cette raison, la première partie du livre s'intéresse aussi bien aux représentations de la main dans les feuilles volantes qu'à l'aspect maniable de cette dernière. À cette occasion, l'auteur revient sur les liens entre image et main, main et mot, main et techniques. La seconde partie s'intéresse quant à elle aux instruments optiques et à la manière dont ceux-ci influencent la vision humaine. L'auteur entend montrer que le processus de codification opéré par les médias est responsable du fait que les instruments d'optique font leur entrée « en tant qu'outils de visualisation » dans les feuilles volantes.

4 Si l'appareil théorique de l'ouvrage obscurcit parfois le propos, les analyses précises des feuilles volantes, notamment de celles qui emploient le motif de la main dans le cadre mnémotechnique des catéchismes ou encore celles qui analysent les gravures de batailles de Hogenberg pendant la " guerre des Huguenots » (p. 225-228), sont d'un grand intérêt, même si l'approche choisie brise toute forme de chronologie et interdit toute contextualisation des objets choisis.

Naïma Ghermani (Université Grenoble II) 